\title{
Investigation of Methods for Determining Stress Distribution Including the "Head on Web" Effect
}

\author{
M. URBAnEK* AND M. Mirocha \\ Cracow University of Technology, Kraków, Poland \\ (Received September 12, 2018; in final form September 18, 2018)
}

\begin{abstract}
This work presents research on the distribution of tangential stresses and normal in rail type 60 E1 and 49 $\mathrm{E} 1$ in individual locations, i.e. in the axis of the rail head, at the junction between the head and the neck, in the central axis, and on the foot of the rail. The tests were performed using the empirical, analytical and numerical methods. The analyses included the occurrence of the "head on web" effect.
\end{abstract}

DOI: 10.12693/APhysPolA.134.1187

PACS/topics: "head on web" effect, rail stress distribution, methods of measuring stresses

\section{Introduction}

Nowadays, Vingoles wide-foot rails are used in the railways. The cross-section of the rails has been shaped over decades, now the cross-section consists of a head, neck, and foot with an appearance derived from the double t-section shape. Double t-sections are known for their advantages at work bending under load.

The problem of the distribution of strains was investigated by Timoshenko and Langer [1, 2].

The stress distribution due to the bending behavior is consistent with the conventional prismatic beam theory.

The stress distribution is due to

$$
\sigma=\frac{M \times \xi}{I},
$$

where $\sigma$ - flexural stress in $\mathrm{N} / \mathrm{mm}^{2}, \xi$ - distance between the point under consideration and neutral axis in $\mathrm{mm}, M$ - bending moment in $\mathrm{N} \mathrm{m}^{2}, I$ - moment of inertia in $\mathrm{mm}^{4}$.

The first static solution, formulated in 1938 by Ludwig [2], was a Bernoulli-Euler beam on a resilient substrate. One of the basic assumptions of Winkler [5] and Zimmerman [8] is to determine the boundary between the head and the neck of the rail. The presented approach also assumed:

- linear-elastic material behaviour;

- plane section remain plane (Bernoulli's hypothesis);

- the deflection are very small in relations to the length of beam under consideration;

- the base (supporting medium) is schematized as an assembly of linear-elastic springs;

- there are no shear stresses at the beam/base interface and in the base [7].

Approach to the problem of stress determination presented by Eisenmann in 1965 [6] is similar to that proposed by Timoshenko and Langer. Eisenmann, however, defined the stiffness of the neck differently.

\footnotetext{
* corresponding author
}

A close comparison of both approaches with their compliance with laboratory research was carried out in 1982 by Kolvoort and Woestenburg at Delft University of Technology [7]. The paper presents not only the comparison of mathematical models, but also numerical analysis (computer) and laboratory tests. The usefulness of the Eisenmann approach has been determined to calculate the average stresses generated by bending, but the exception is the centrally loaded rail. Both laboratory measurements using strain gauges and computerized methods are suitable for determining bending stress distributions.

Various physical and mechanical forces act on the rail, which affect stress. The effects taking place in rails include:

- Thermal stress.

- Stress resulting from longitudinal movement of rails, as well as rails with sleepers.

- The own stress rail created after relieving it from external forces, while deforming it. It affects the strength of the rail. At the time of its creation, the rail is not subject to any external loads. The internal stress has a significant effect on the operational properties of the rails, because in extreme cases it can lead to their rupture [10, 11].

- Stress, which has its source at the moment of occurrence of operational interactions, such as the own weight of the train or the traction force and braking the vehicle.

The "head on web" effect is based on the following basic assumptions:

- the rail division into two parts: head and neck,

- the head is considered as a beam that rests on the elastic neck.

The deflections of the rail head in relation to the neck and foot are small in relation to the deflection of the entire rail.

Measurement of deformations can be made using strain gauges, this method is very simple but its disadvantage is that the strain gauges are expensive, time-consuming in the installation and measure only deformations at one 
point. An alternative to extensometers are fiber optic sensing $[12,13]$. Fiber optic technology can be divided into two main types: discrete sensors, including fiber Bragg gratings (FBG) and the Fabry-Perot interferometers, and distributed sensors, including the Brillouin, Raman, and Rayleigh measurement techniques. Measurement of deformation using fiber require a compromise between the accuracy of the measurement, fiber length, spatial resolution, and measurement frequency. Until now, FBG and Brillouin methods have been used to measure deformations in railway rails. Most often, optical fiber methods are used to monitor the work of the railway track [13-15].

Another solution for measuring the deformation of the rail is to mount the measuring system on the rail vehicle. The laser Doppler sensors [17] and accelerometers on a moving rail vehicle [18] have been successfully applied to the boogies and the rail using line lasers [16]. The advantage of the presented solutions over point measurements is the ability to measure large track lengths. However, in some cases the measurement of the absolute deformation of the rail is necessary.

One of the point measurement techniques eliminating problems with other point methods is the use of highspeed cameras [19] in combination with digital image analysis methods, such as partial velocimetry, PIV or digital image correlation, DIC [20, 21].

In laboratory tests, the choice of the measurement method of deformation using strain gauges was influenced by several elements: small dimensions of the sample, measurement only at characteristic points, the possibility of multiple use of the same sample for several variants of force action.

\section{Laboratory tests}

Laboratory tests were carried out on two types of rails $60 \mathrm{E} 1$ and $49 \mathrm{E} 1$. They consisted of a static load $(100 \mathrm{kN})$ on the supported rail (Fig. 1). The load cycles have been repeated five times. The results were measured using
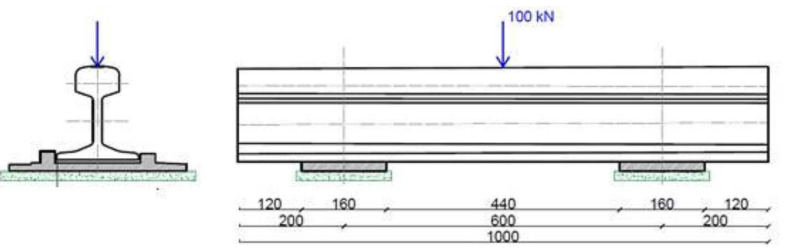

Fig. 1. Scheme of support and application of force for $60 \mathrm{E} 1$ and $49 \mathrm{E} 1$ bus - units in $\mathrm{mm}$.

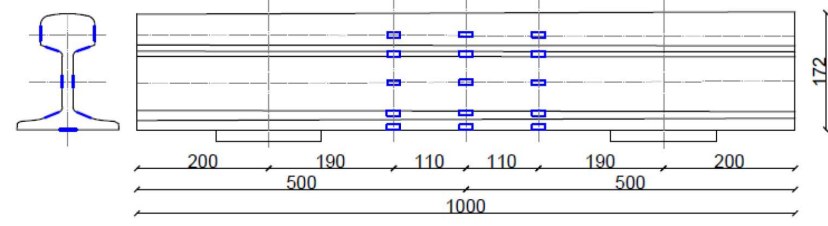

Fig. 2. Location of the strain gauges in cross-section and lateral view - units in mm. strain gauges placed on the rail surface at specific points. The location of the strain gauges was selected in the rail neutral axis, the rail head axis and the foot (Fig. 2).

Results of laboratory tests show deformations of individual strain gauges depending on strength and time. With strain gauges and compression, you can use the relationship between stress and the strain defined by Hooke's law, described by the formula

$$
\sigma=E \varepsilon,
$$

where $E-$ Young's modulus $=210 \mathrm{GPa}, \varepsilon-$ linear deformation.

From the laboratory tests carried out on the 60 E1 rail, the loads of which are visible in Fig. 2, the results of strain gauges for a force equal to $100 \mathrm{kN}$ were selected. Figure 3 presents selected data in the middle of the span rails, symmetrically on both sides (the number of T8T11 and T26-T29), and the strain gauge located at the base of the rails (number T38). A similar range of strain gauges is used for rail $49 \mathrm{E} 1$ (Fig. 5).

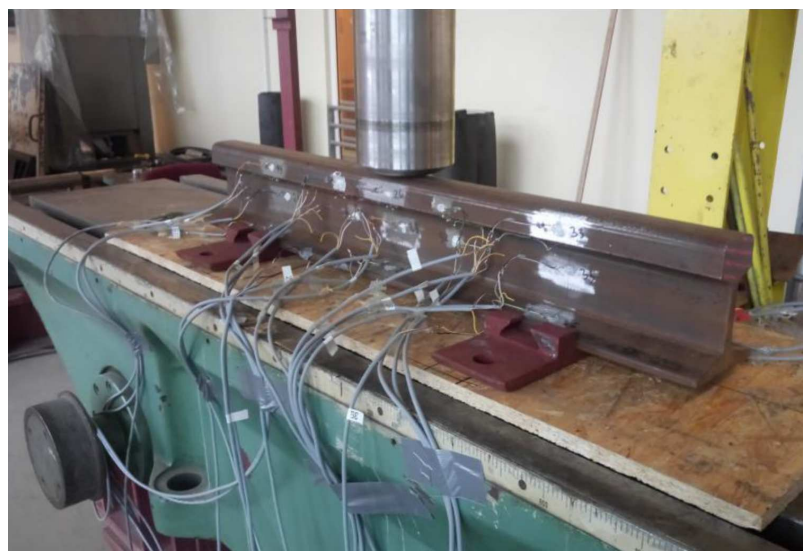

Fig. 3. Laboratory station.
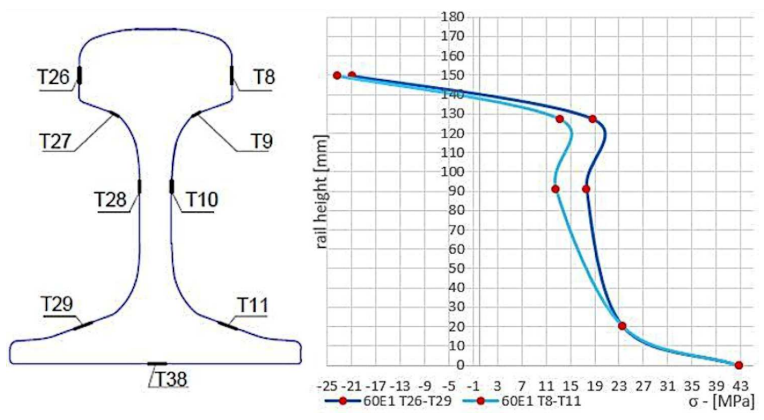

Fig. 4. Diagram of normal stress values in the rail 60 E1 for individual strain gauges [11].

Figures 4 and 5 show the inaccuracy of the vertical force applied in the axis of the track, hence the discrepancy in values. Normal stress values obtained at points located on the same height of the rails do not overlap. The maximum difference of stress was $12.89 \mathrm{MPa}$ for strain gauges no. T8 and T26 located in the axis of the rail head $49 \mathrm{E} 1$. Differences for the remaining strain gauges are located in a range from $0 \mathrm{MPa}$ to $8.817 \mathrm{MPa}$. 

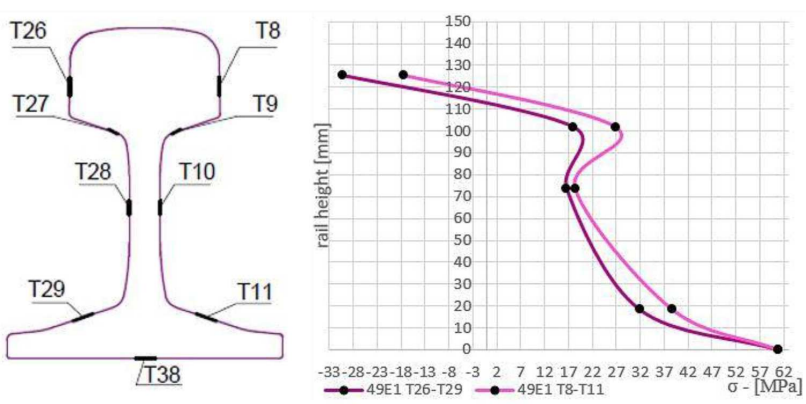

Fig. 5. Diagram of normal stress values in the rail 49 E1 for individual strain gauges [11].

\section{Development and analysis of the model}

In the present case we considered a simply supported beam spot - analytical approaches. It is freely supported and loaded with force concentrated in the middle of the span presented in Fig. 6. Calculation was carried out for simplified cross-section presented in Fig. 7.

Simplified cross-section of rail $60 \mathrm{E} 1$ has got the same area and moment of inertia like normal rail 60 E1 crosssection. Figure 8 shows distribution of tangential stresses of simplified cross-section.

The dynamic development of technologies in the field of computational methods has contributed to the creation of much more accurate and functional computer programs that are based on the finite element method

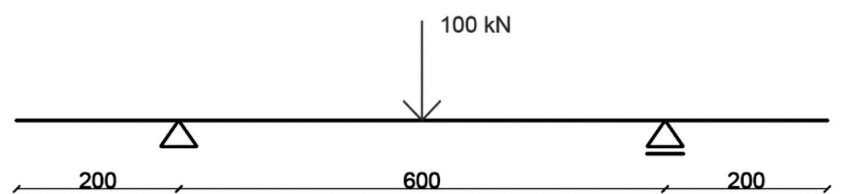

Fig. 6. Schema of support and loaded of the beam units in $\mathrm{mm}$.

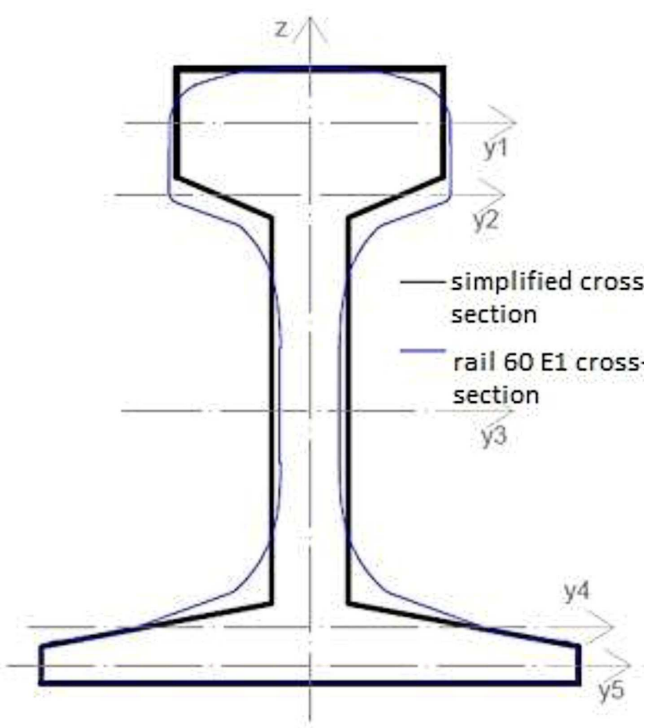

Fig. 7. Simplified cross-section of rail 60 E1.

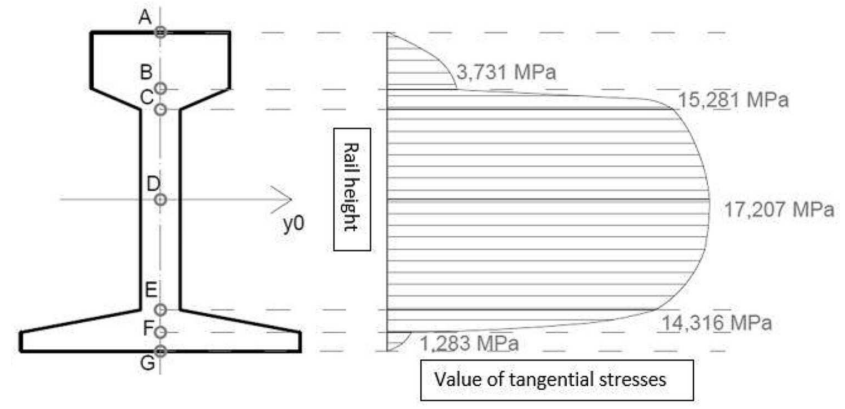

Fig. 8. Diagram of tangential stresses for simplified cross-section of rail $60 \mathrm{E} 1$.

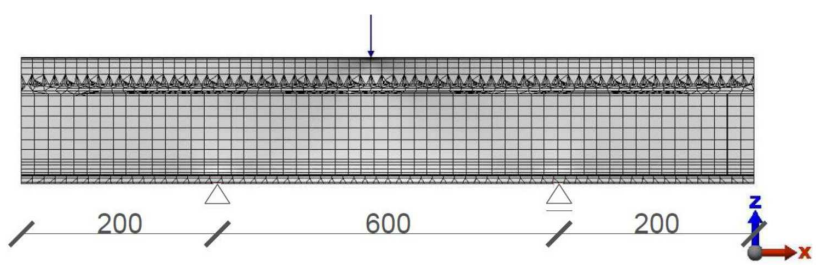

Fig. 9. Schema of support and loaded of the rail (60 E1/49 E1) in Autodesk Simulation - units in mm.

(FEM). This method is widely used in many engineering calculations. Considering the above method in the calculations concerning the stress testing of rails, it has high validity [10]. In the numerical approach models of both cross-sections of rails were used. Figure below (Fig. 9) shows schema of support and loaded of the rail 3D model.

Obtained results of normal stresses are presented in Figs. 10 and 11. In the case of tangential stresses, the values are presented in Figs. 12 and 13. Values are presented by means of a color scale.

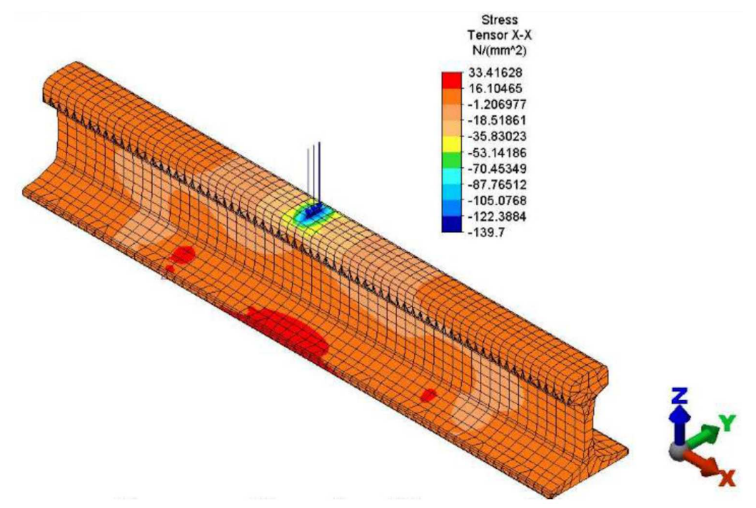

Fig. 10. Distribution of normal stresses in 60 E1 rail.

The following table shows the normal stress distribution resulting from rail $60 \mathrm{E} 1$ depending on the place of measurement (Table I) and accepted test method. These results indicate the differences in the sizes of these stresses in relation to research and methodology used. Demonstrated research revealed that stress values in all studies indicate to be negative on both end of the head and in its axis. Only analytical tests 
Comparative table of normal stresses for rail $60 \mathrm{E} 1$

\begin{tabular}{l|c|c|c|c|c|c}
\hline \hline \multirow{2}{*}{ Method of calculation } & \multicolumn{4}{c}{ Normal stress [MPa] rail 60 E1, vertical load 100 kN } \\
\cline { 2 - 6 } & $\mathrm{A}$ & $\mathrm{B}$ & $\mathrm{C}$ & $\mathrm{D}$ & $\mathrm{E}$ & $\mathrm{F}$ \\
\hline laboratory test & - & -22.107 & 16.081 & 12.640 & 23.688 & 42.798 \\
analytical test (simplify cross-section) & -44.324 & -33.261 & -22.229 & 0 & 30.309 & 40.131 \\
numerical calculation - Autodesk Simulation Multiphysics & - & -7.793 & 9.091 & 5.733 & 15.384 & 33.286
\end{tabular}

were carried out for the edge of the head, because the obtained results are unreliable due to numerical methods. In contrast to the other tests carried out, in the case of a simplified analytical model, the moment of transition from compression to stretching is in the central axis of the rail. For the remaining studies, positive values appeared earlier, already at the level of the head and neck connection. This situation results from the fact that when using the analytical method, the values were counted in the symmetry axis of the bus, while for the others they were read on the external surface.

Results obtained on the basis of laboratory tests and calculations using the Autodesk Simulation Multiphysics exhibit similarities, on changes of stress. This change is visible between the head and the connection of the head to the neck, where the compressive stresses change in stretching stress.

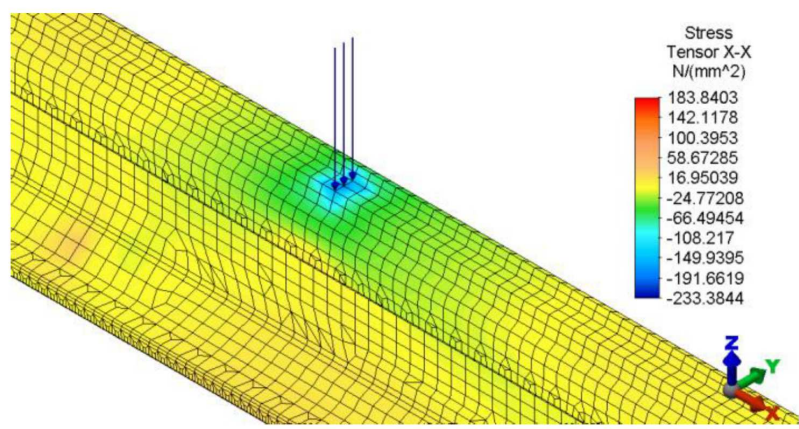

Fig. 11. Distribution of normal stresses in 49 E1 rail.

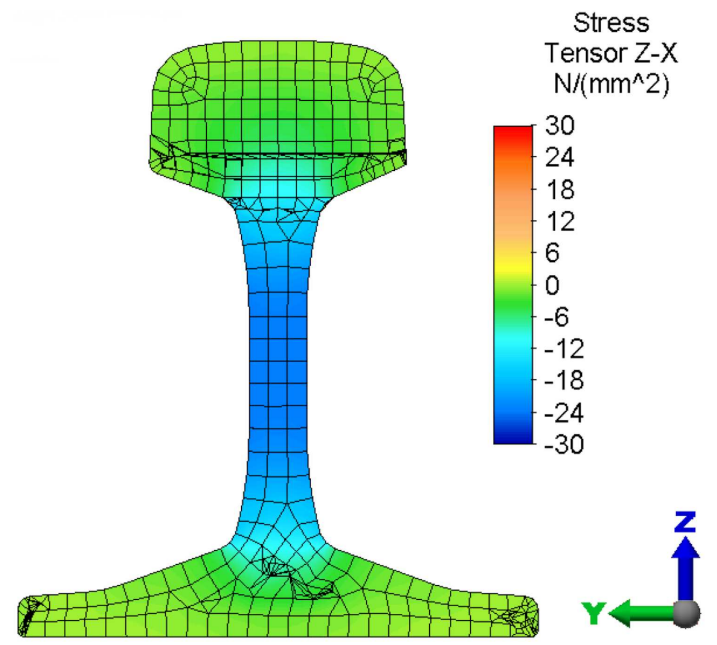

Fig. 12. Distribution of tangential stresses in $60 \mathrm{E} 1$ rail.
To complement, Table I presents a line chart showing the comparison between the normal stresses of rail $60 \mathrm{E} 1$ for the selected calculation methods.

The graph shows that the stress distribution from the beam model, the zero point, is at the rail height of $80 \mathrm{~mm}$, while the remaining lines indicate a zero value in the range $140-150 \mathrm{~mm}$ of the rail height. The discrepancy between the model bar and the other models in the zone of application of the load occurs as a result

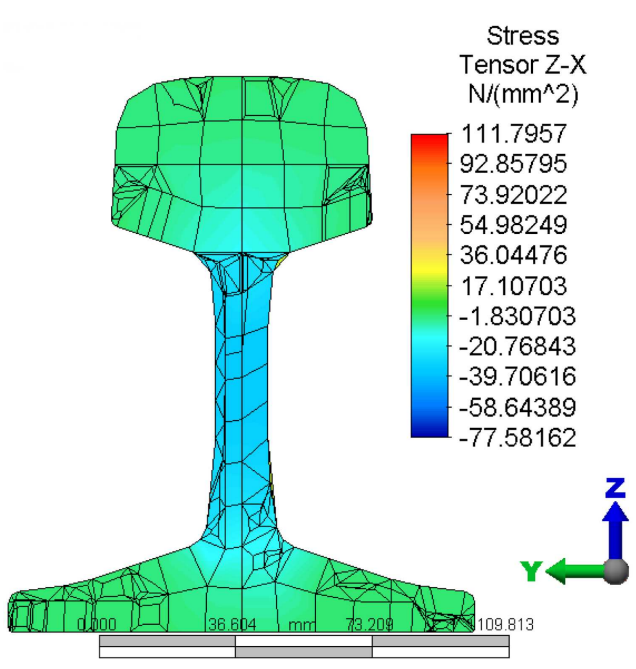

Fig. 13. Distribution of tangential stresses in 49 E1 rail.

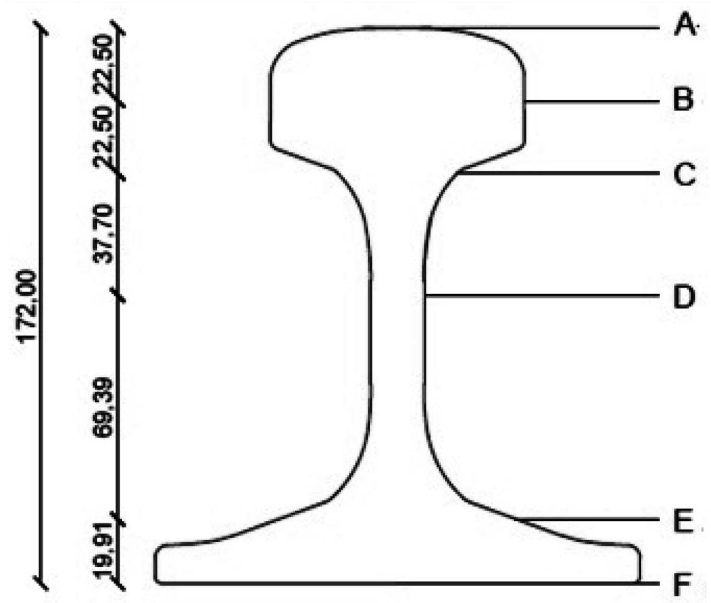

Fig. 14. Diagram of selected points for rail stress analysis $60 \mathrm{E} 1$ - units in mm. A - edge of rail head, B - rail head neutral axis, $\mathrm{C}$ - connection of head and neck, D - rail neutral axis, $\mathrm{E}$ - rail foot, $\mathrm{F}$ - rail basis. 


\begin{tabular}{l|c|c|c|c|c|c}
\hline \multirow{2}{*}{ Method of calculation } & \multicolumn{5}{|c}{ Tangential stress [MPa] rail 60 E1, vertical load 100 kN } \\
\cline { 2 - 6 } & $\mathrm{A}$ & $\mathrm{B}$ & $\mathrm{C}$ & $\mathrm{D}$ & $\mathrm{E}$ & $\mathrm{F}$ \\
\hline analytical test (simplify cross-section) & 0 & -2.891 & -15.281 & -17.207 & -1.283 & 0 \\
numerical calculation - Autodesk Simulation Multiphysics & -0.411 & -6.250 & -11.580 & -19.426 & -0.839 & -0.057
\end{tabular}

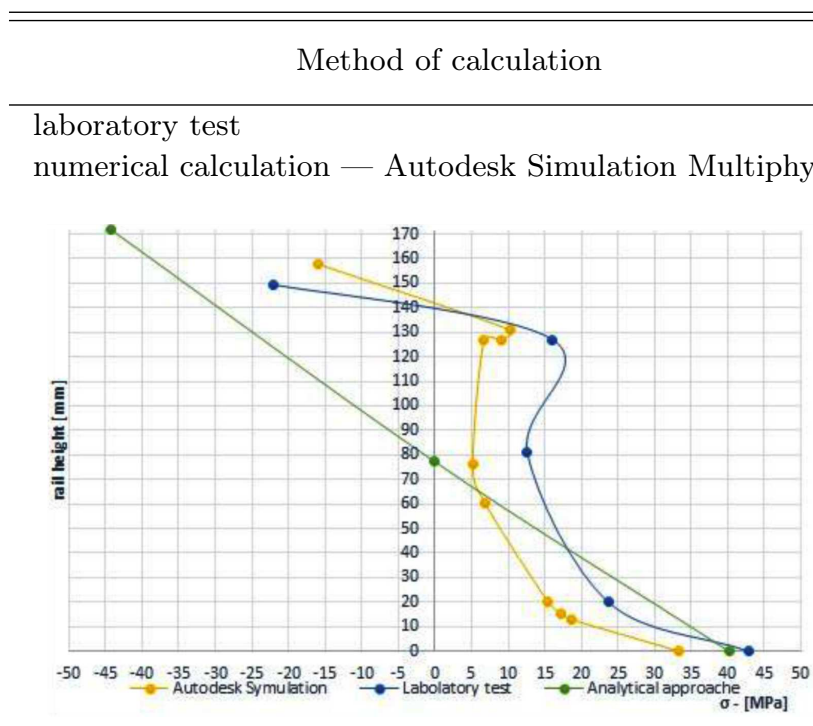

Fig. 15. Comparison between the normal stresses of rail $60 \mathrm{E} 1$ for the selected calculation methods.

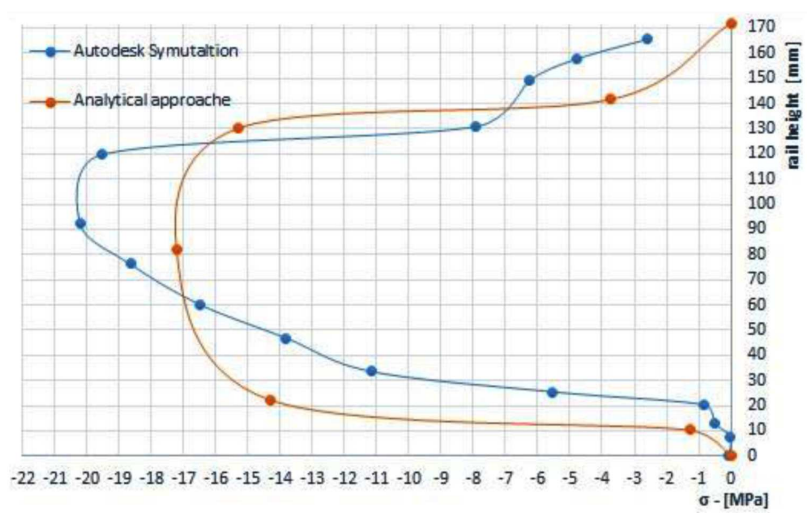

Fig. 16. Compared values of tangential stresses for rail $60 \mathrm{E} 1$.

of the compression of the rail with the stretching in the direction of the rail axis. Stresses on the basis of the rails shown in all the test methods have positive values and are located between 34 and $43 \mathrm{MPa}$. Noticeable change in stresses in the graph indicates the range of stress values from $-28 \mathrm{MPa}$ to $+16 \mathrm{MPa}$, in analysed case it can be concluded about the effect "head on web" at the height of the head-neck connection, between $140 \mathrm{~mm}$ and $150 \mathrm{~mm}$.

Data were analysed on a tangential stresses in the rail $60 \mathrm{E} 1$ loaded vertical force, in this case equal to $100 \mathrm{kN}$, calculated analytical method (simplified cross-section) and the numerical one for the real cross-section. The

\begin{tabular}{l|c|c|c|c|c}
\multicolumn{5}{c}{ Normal stress [MPa] rail $49 \mathrm{E} 1$, vertical load $100 \mathrm{kN}$} \\
\hline A & B & C & D & E & F \\
\hline- & -23.807 & 22.428 & 17.562 & 35.294 & 60.896 \\
- & -19.105 & 21.095 & 2.519 & 12.484 & 34.371
\end{tabular}

results of the calculations are summarized in the following Table II. The location of points for which the values are summarized in Table II, is illustrated in Fig. 17.

A graphical representation of the values from the table above (Table II) is shown in detail in the graph Fig. 16. From the graph below it can be concluded that the stress distribution for the simplified cross-section (analytical method) and the real cross-section (numerical method) shows discrepancies in the neutral axis of the rail. The difference is $-2.219 \mathrm{MPa}$, which is about $8.75 \%$.

The normal stresses for the $49 \mathrm{E} 1$ profile rail were also analysed. In this case only there were used two methods: analytical and numerical. The collected results are both in Table III and chart below - Fig. 18.

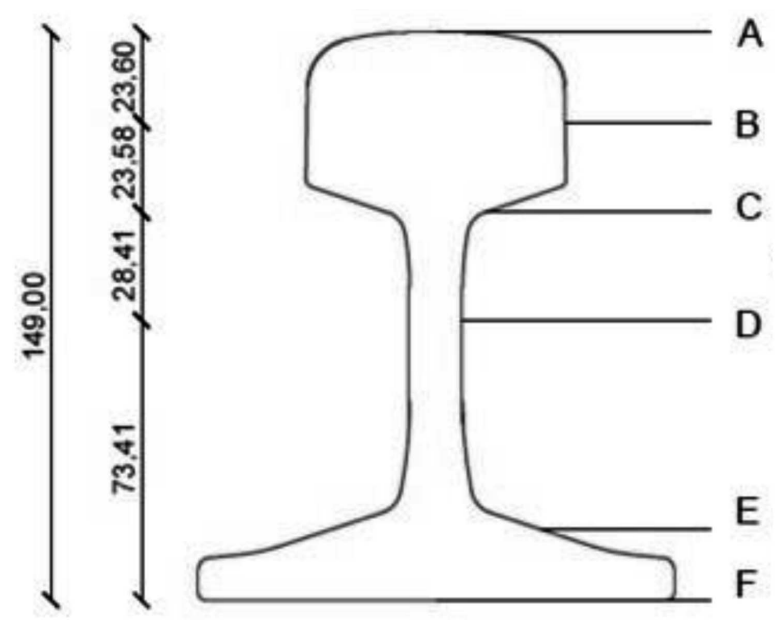

Fig. 17. Diagram of selected points for rail stress analysis $49 \mathrm{E} 1$ - units in mm. A - edge of rail head, B - rail head neutral axis, C - connection of head and neck, D - rail neutral axis, $\mathrm{E}$ - rail foot, $\mathrm{F}$ - rail basis.

For one point, located on the edge of the rail head, no correct values were obtained that could be analyzed, as was the case with the 60E1 bus. Negative values from selected points appeared only on the axis of the head and they have reached value: $-3.177 \mathrm{MPa}$ (laboratory) and -19.105 MPa (Autodesk Simulation Multiphysics). In all other places of the rail, positive values appeared, but their increments were not the same. In both cases, the biggest change in value, about $40 \mathrm{MPa}$, occurred between 
the head axis and its connection with the neck. In the next place of the rail, i.e. in its central axis, the magnitudes of stress for two cases have decreased, respectively:

- from 22.428 $\mathrm{MPa}$ to $17.562 \mathrm{MPa}$ (decrease by $4.866 \mathrm{MPa})$,

- from 21.095 MPa to 2.519 $\mathrm{MPa}$ (decrease by 18.576 MPa).

In the analysis carried out with the Autodesk Simulation Multiphysics program (numerical approach), the highest value of tensile stress was recorded at the base of the rail and amounted to $60.896 \mathrm{MPa}$. The analogous situation took place using the second calculation method, and the value obtained was 34.337 MPa.

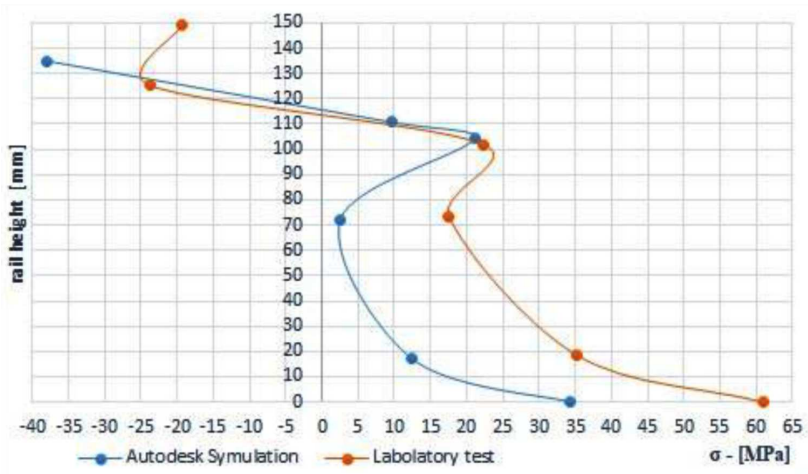

Fig. 18. Comparison between the normal stresses of rail $49 \mathrm{E} 1$ for the selected calculation methods.

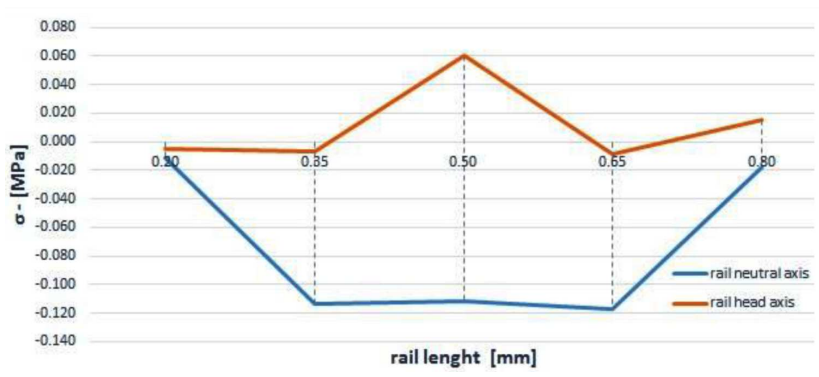

Fig. 19. Compared values of stresses for rail head axis and rail neutral axis - rail $60 \mathrm{E} 1$.

The above graph (Fig. 19) shows the magnitude of stresses, depending on the rail height. From the rail head axis (in the graph $-25 \mathrm{MPa}$ ) to the connection of the head with the neck (in the graph, the point corresponding to the size of $23 \mathrm{MPa}$ ), the stresses obtained from the laboratory test and calculations from the Autodesk Simulation overlap. Below this point there are discrepancies. The shape of line is identical, but their size vary.

Deference between stresses of rail neutral axis or head axis can be observed in the graph below. Maximum value of deferments is in in the place where the force is applied, and is around $172 \mathrm{MPa}$.
Based on the analysis of simplified models [9] and laboratory tests, the additional effects in the rail (except the vertical bending of the rail as a whole) are significant. Bending the rail head relative to the neck gives the same row of axial stresses as bending the entire rail. However, the linear range (significant influence from the point of load application) of the "head on web" effect is almost 25 times smaller.

\section{Summary}

The stress distributions calculated both in the numerical approach and in the laboratory tests are similar, the shape of the distribution is maintained, but there are differences in value. Both methods for determining stress distribution are suitable serviceable method for the purpose. As a result of the "head on web" effect, which changes the position of the zero stress value, it should be included in the analytical model. In the beam (analytic) model, the zero value of stresses is at the rail height of $80 \mathrm{~mm}$, while the other distributions indicate a zero value between 140 and $150 \mathrm{~mm}$ of the rail height.

The greatest fluctuations in stress values could be observed between the head axis and the place where the head and neck joined.

\section{References}

[1] S. Timoshenko, "Method of analysis of static and dynamic stresses", in: Proc. 2nd Int. Congress on Applied Mechanics, Zurich, 1926, p. 407.

[2] S. Timoshenko, B.F. Langer, "Stresses in railroad track", No. AMP-54-26, 1973.

[3] K. Ludwig, "Deformation of rail elasticity supported of infinite length by load moving at a constant velocity", in: Proc. 5th Int. Congress Appl. Mech., 1938, p. 650 .

[4] E. Winkler, Die Lehre von der Elasticitaet und Festigkeit, Dominicus, Prag 1867.

[5] H. Zimmermann, Die Berechnung des Eisenbahnoberbaus, Ernst, Nachdruck der 3. Auflage von 1941, Berlin.

[6] J. Eisenmann, "Stress distribution in the permanent way due to heavy axle load and high speeds", Techanical University of Munich, 1969, Contract No. 71-622-3.

[7] A.J. Kolvoort, T. Woestenburg, Heron J. 27, 21 (1982).

[8] J. Kukulski, Problemy Kolejnictwa 5125 (2007) (in Polish).

[9] W. Czyczuła, Drogi Kolejowe 32, 12 (1988) (in Polish).

[10] M. Urbanek, W. Czyczuła, "Analysis of the state of stresses and displacements in railway rails with different cross-sections", in: Zeszyty Naukowo-Techniczne Stowarzyszenia Inżynierów i Techników Komunikacji Rzeczpospolitej Polskiej, Oddziałw Krakowie, Series: Materiały Konferencyjne, "Modern technologies and management systems for rail transport", Zakopane, 2016, p. 191 (in Polish).

[11] M. Mirocha, M.Sc. Thesis, Politechnika Krakowska, Kraków, 2018 (in Polish). 
[12] L.N. Wheeler, E. Pannese, N.A. Hoult, H. Le, Transportat. Geotechn. 14, 70 (2018).

[13] A. Iele, V. Lopez, A. Laudati, N. Mazzino, G. Bocchetti, A. Cutolo, A. Cusano, in: Proc. 8th EWSHM, 2016.

[14] Chu-Liang Wei, Chun-cheung Lai, Shun-yee Liu, W.H. Chung, Tin Kin Ho, Hwa-yaw Tam, S.L. Ho, A. McCusker, J. Kam, K.Y. Lee, IEEE Sensors J. 10.12, 1905 (2010).

[15] M.L. Filograno, P. Corredera, M. Rodriguez-Plaza, A. Andres-Alguacil, M. Gonzalez-Herraez, IEEE Sensors J. 13.12, 4808 (2013).

[16] C.D. Norman, Ph.D. Thesis, University of Nebraska, Lincoln 2004.
[17] S. Rasmussen, J.A. Krarup, G. Hildebrand, in: Proc. 6th Int. Conf. on the Bearing Capacity of Roads, Railways and Airfields, Vol. 8, 2002, pp. 53-60.

[18] T.R. Sussmann, in: Proc. Railway Engineering Conf., London 200\%.

[19] D. Bowness, A.C. Lock, W. Powrie, J.A. Priest, D.J. Richards, Proc. Institution of Mechanical Engineers Part F: J. Rail Rapid Transit 221, 13 (2007).

[20] D.J. White, W.A. Take, M.D. Bolton, Geotechnique 53, 619 (2003).

[21] C.A. Murray, W.A. Take, N.A. Hoult, Canad. Geotechn. J. 52, 141 (2014). 